\title{
TL-IDEALS OF TL-SUBNEAR-RINGS
}

\author{
J.D. Yadav. \\ S.G.M.College, Karad, Maharashtra, India \\ Email: jdy1560@yahoo.co.in \\ Y.S. Pawar. \\ Department Of Mathematics, \\ Shivaji University, Kolhapur, Maharashtra, India \\ Email:y_s_pawar@yahoo.com
}

Received 20.07.2011

Accepted 08.01.2012

\begin{abstract}
The aim of this paper is to introduce and study TL-ideals of TL-subnear-rings. Also we define Tsum, T-difference and T-product of L-subsets of a near-ring $\mathrm{R}$ and obtain their properties.
\end{abstract}

Key words: Fuzzy set, TL-subnear-ring, TL-ideal, Homomorphism, Near-ring

\section{Introduction}

Near-Ring is a generalized structure of a ring. The theory of fuzzy sets was introduced by Zadeh [15] .The fuzzy set theory has been developed in many directions by the research scholars. Goguen [9] introduced the concept of L-fuzzy sets. Rosenfeld [13] first introduced the fuzzification of the algebraic structures and defined fuzzy subgroups. Anthony and Sherwood [3], Asaad and Abou-zaid [4], Akgul [2], Das [6], Dixit, Bhambri and Kumar [7] contributed the theory of fuzzy subgroups. Fuzzy ideals of rings are first defined by Liu. [11] and the study was continued by many other researchers to extend the concepts.

Abou-Zaid [1] introduced the notion of fuzzy R-subgroups and fuzzy ideals of near-rings. Dutta and Biswas [8] introduced fuzzy and fuzzy cosets of fuzzy ideals of near-rings. Cheng, Mordeson and Yandong [5] have discussed TL-subnear-rings and TL-ideals of a ring.

As in ring theory, it is interesting to fuzzify some substructures of near-ring. Hence our aim in this paper is to study TL-ideals of TL-subnear-rings and to characterize them.

\section{Preliminaries}

We recall some definitions for the sake of completeness.

Definition (2.1) [10]:By a near-ring we mean a non-empty set $\mathrm{R}$ with two binary operations ' + ' and '.' satisfying the following axioms:

(i) $(\mathrm{R},+)$ is a group, 
(ii) $(\mathrm{R}, \cdot)$ is a semi-group,

(iii) $\mathrm{x} \cdot(\mathrm{y}+\mathrm{z})=\mathrm{x} \cdot \mathrm{y}+\mathrm{x} \cdot \mathrm{z}$ for all $\mathrm{x}, \mathrm{y}, \mathrm{z} \in \mathrm{R}$.

Precisely speaking, it is a left near-ring because it satisfies the left distributive law. We will use the word "near-ring" instead of "left near-ring". We denote xy instead of $x \cdot y$. Note that $\mathrm{x} 0=0$ and $\mathrm{x}(-\mathrm{y})=-\mathrm{xy}$, but $0 \mathrm{x} \neq 0$ for $\mathrm{x}, \mathrm{y} \in \mathrm{R}$.

Definition (2.2) [1, 8]: An ideal I of a near-ring $R$ is a subset of $R$ such that

(i) $(\mathrm{I},+)$ is a normal subgroup of $(\mathrm{R},+)$,

(ii) $\mathrm{RI} \subseteq \mathrm{I}$,

(iii) $(r+i) s-r s \in I$ for all $i \in I$ and $r, s \in R$.

Note that if I satisfies (i) and (ii) then it is called a left ideal of R.

If I satisfies (i) and (iii) then it is called a right ideal of $\mathrm{R}$.

Definition (2.3): A binary operation $\mathrm{T}$ on a lattice $\mathrm{L}$ is called a t-norm if it satisfies the following conditions:

(i) $\mathrm{T}(\mathrm{T}(\mathrm{a}, \mathrm{b}), \mathrm{c})=\mathrm{T}(\mathrm{a}, \mathrm{T}(\mathrm{b}, \mathrm{c}))$,

(ii) $\mathrm{T}(\mathrm{a}, \mathrm{b})=\mathrm{T}(\mathrm{b}, \mathrm{a})$,

(ii) $\mathrm{b} \leq \mathrm{c} \Rightarrow \mathrm{T}(\mathrm{a}, \mathrm{b}) \leq \mathrm{T}(\mathrm{a}, \mathrm{c})$,

(iv) $\mathrm{T}(\mathrm{a}, 1)=\mathrm{a}$,

for all $\mathrm{a}, \mathrm{b}, \mathrm{c} \in \mathrm{L}$.

Definition (2.4): A fuzzy set $\mu$ in a near-ring $\mathrm{R}$ is a function $\mu$ : $\mathrm{R} \rightarrow[0,1]$.

Definition (2.5): Let $\mu$ be a fuzzy set in a near-ring $R$ and $t \in[0,1]$. Then the crisp set $\mu_{t}$ $=\{\mathrm{x} \in \mathrm{R} \mid \mu(\mathrm{x}) \geq \mathrm{t}\}$ is called a $\mathrm{t}$-level subset or $\mathrm{t}$-cut of $\mu$.

\section{TL-ideals of TL-subnear-ring}

Let $\mathrm{R}$ be a near-ring and $\mathrm{L}$ be a complete lattice.

Definition (3.1)[14]: An L-subset $\mu$ of a near-ring R is called a TL-subgroup of $R$ if it satisfies the following conditions:

(i) $\mu(0)=1$,

(ii) $\mu(-\mathrm{x}) \geq \mu(\mathrm{x})$,

(iii) $\mu(\mathrm{x}+\mathrm{y}) \geq \mu(\mathrm{x}) \mathrm{T} \mu(\mathrm{y})$.

for all $\mathrm{x}, \mathrm{y} \in \mathrm{R}$.

Definition (3.2)[14]: An L-subset $\mu$ of a near-ring $R$ is called a TL- subnear-ring of $R$ if it satisfies the following conditions: 
(i) $\mu(0)=1$,

(ii) $\mu(-x) \geq \mu(x)$,

(iii) $\mu(\mathrm{x}+\mathrm{y}) \geq \mu(\mathrm{x}) \mathrm{T} \mu(\mathrm{y})$,

(iv) $\mu(\mathrm{x} y) \geq \mu(\mathrm{x}) \mathrm{T} \mu(\mathrm{y})$ for all $\mathrm{x}, \mathrm{y} \in \mathrm{R}$.

Remarks (3.3): (i) When $\mathrm{T}=\wedge$, a TL-subnear-ring is called L-subnear-ring.

(ii)The set of all TL- subnear-rings of R and set of all L- subnear-rings of $\mathrm{R}$ are denoted by $\mathrm{TL}(\mathrm{R})$ and $\mathrm{L}(\mathrm{R})$ respectively.

(iii) If $\mathrm{L}=[0,1]$, $\mathrm{TL}$ - subnear-ring and $\mathrm{L}$ - subnear-ring of $\mathrm{R}$ are known as $\mathrm{T}$-fuzzy subnear-ring and fuzzy subnear-ring of $\mathrm{R}$ respectively.

Definition (3.4)[14]: An L-subset $\mu$ of a near-ring $R$ is called a TL-ideal of $R$ if

(i) $\mu(0)=1$,

(ii) $\mu(-x) \geq \mu(x)$,

(iii) $\mu(\mathrm{x}+\mathrm{y}) \geq \mu(\mathrm{x}) \mathrm{T} \mu(\mathrm{y})$,

(iv) $\mu(\mathrm{y}+\mathrm{x}-\mathrm{y}) \geq \mu(\mathrm{x})$,

(v) $\mu$ (xy) $\geq \mu(y)$,

(vi) $\mu((x+i) y-x y) \geq \mu(i)$ for

for all $\mathrm{x}, \mathrm{y}, \mathrm{i} \in \mathrm{R}$.

Remarks (3.5) : (i) If $\mu$ satisfies (i), (ii), (iii), (iv) and (v) then it is TL-left ideal of $\mathrm{R}$ and if $\mu$ satisfies (i), (ii), (iii), (iv) and (vi) then it is TL-right ideal of R.

(ii) When $\mathrm{T}=\wedge$, a TL-left ideal and TL-right ideal are known as L-left ideal and L-right ideal respectively.

(iii) The set of all TL- left ideals and TL-right ideals of R are denoted by $\mathrm{TLI}_{1}(\mathrm{R})$ and $\mathrm{TLI} \mathrm{I}_{\mathrm{r}}(\mathrm{R})$ respectively.

(iv) When $\mathrm{T}=\wedge$, set of all L- left ideals and L-right ideals of $\mathrm{R}$ are denoted by $\mathrm{LI}_{1}(\mathrm{R})$ and $\mathrm{LI}_{\mathrm{r}}(\mathrm{R})$ respectively.

(v) When $\mathrm{L}=[0,1]$ TL-left ideals and TL-right ideals are known as T-fuzzy left ideals and $T$-fuzzy right ideals of $R$ respectively and when $T=\wedge$, they are known as fuzzy left ideals and fuzzy right ideals of $\mathrm{R}$ respectively.

Now we define TL-ideals of TL-subnear-rings:

Definition (3.6): A function $\mu: \mathrm{R} \rightarrow \mathrm{L}$ is called an $\mathrm{L}$-subset of $\mathrm{R}$.

The set of all $\mathrm{L}$-subsets of $\mathrm{R}$ is called the $\mathrm{L}$-power set of $\mathrm{R}$ and is denoted by $\mathrm{L}^{\mathrm{R}}$.

Definition (3.7): Let $\mu \in \mathrm{L}^{\mathrm{R}}, \gamma \in \mathrm{TL}(\mathrm{R})$ and $\mu \leq \gamma$. Then 
(1) $\mu$ is a TL-left ideal of $\gamma$ if

(i) $\mu$ is a normal TL-subgroup of $(\mathrm{R},+)$,

(ii) $\mu(x y) \geq \gamma(x) T \mu(y)$ for all $x, y \in R$.

(2) $\mu$ is a TL-right ideal of $\gamma$ if

(i) $\mu$ is a normal TL-subgroup of $(\mathrm{R},+)$,

(ii) $\mu((x+i) y-x y) \geq \mu($ i $) T \gamma(y)$ for all $x, y, i \in R$.

(3) $\mu$ is said to be TL-two sided or TL-ideal of $\gamma$ if

(i) $\mu$ is a normal TL-subgroup of $(\mathrm{R},+)$,

(ii) $\mu$ is both TL-left and TL-right ideal of $\gamma$.

Remark (3.8): When $T=\wedge$ these ideals will be called as L-left, L-right and

L-two sided ideals of $\gamma$ respectively.

Theorem (3.9): An L-subset $\mu \in L^{R}$ is a TL-right (resp.TL-left) ideal of $R$ if and only if $\mu$ is a TL-right (resp.TL-left) ideal of the TL-subnear-ring $1_{R}$.

Proof: Part (I): Let $\mu \in \mathrm{L}^{\mathrm{R}}$ be a TL-right ideal of R.

Then $\mu((x+i) y-x y) \geq \mu(i) \leq$ for all $x, y, i \in R$.

Now $\mu($ i $)$ T $1_{R}(y) \leq \mu($ i $) \wedge 1_{R}(y)=\mu($ i $)$.

$$
\Rightarrow \mu(\mathrm{i}) \mathrm{T} 1_{\mathrm{R}}(\mathrm{y}) \leq \mu(\mathrm{i}) \leq \mu((\mathrm{x}+\mathrm{i}) \mathrm{y}-\mathrm{xy}) \text {. }
$$

i.e. $\mu((x+i) y-x y) \geq \mu($ i $) T 1_{R}(y)$ for all $x, y, i \in R$.

Hence $\mu$ is a TL-right ideal of the TL-subnear-ring $1_{R}$.

Conversely let $\mu$ be a TL-right ideal of the TL-subnear-ring $1_{R}$.

Therefore $\mu((x+i) y-x y) \geq \mu(i) T 1_{R}(y)$ for all $x, y, i \in R$.

$$
\begin{aligned}
& \Rightarrow \mu((x+i) y-x y) \geq \mu(i) T 1_{R}(y)=\mu(i) . \\
& \Rightarrow \mu((x+i) y-x y) \geq \mu(\text { i }) \text { for all } x, y, i \in R .
\end{aligned}
$$

Hence $\mu$ is a TL-right ideal of $R$.

Part (II): Let $\mu \in \mathrm{L}^{\mathrm{R}}$ be a TL-left ideal of R.

Then $\mu$ is a normal TL-subgroup of $(\mathrm{R},+)$ and $\mu(\mathrm{xy}) \geq \mu(\mathrm{y})$.

Therefore $1_{\mathrm{R}}(\mathrm{x}) \mathrm{T} \mu(\mathrm{y}) \leq 1_{\mathrm{R}}(\mathrm{x}) \wedge \mu(\mathrm{y})=\mu(\mathrm{y})$ for all $\mathrm{x}, \mathrm{y} \in \mathrm{R}$.

$$
\Rightarrow 1_{\mathrm{R}}(\mathrm{x}) \mathrm{T} \mu(\mathrm{y}) \leq \mu(\mathrm{y}) \leq \mu(\mathrm{xy}) .
$$

Hence $\mu$ is a TL-left ideal of the TL-subnear-ring $1_{R}$.

Conversely let $\mu$ be a TL-left ideal of the TL-subnear-ring $1_{R}$. 
Therefore $\mu(x y) \geq 1_{R}(x) T \mu(y)=\mu(y)$.

Hence $\mu$ is a TL-left ideal of $R$.

Theorem (3.10): Let $\mu \in \mathrm{L}^{\mathrm{R}}$ and $\gamma \in \mathrm{L}(\mathrm{R})$.If $\mu$ is L- right (resp.L-left) ideal of $\gamma$ then for every $\mathrm{a} \in \mathrm{L}, \mu_{\mathrm{a}}$ is a right (resp. left) ideal of $\gamma_{\mathrm{a}}$.

Proof: Part (I): Let $\mu$ be L-right ideal of $\gamma$.

Then $\mu((x+i)$ y $-x y) \geq \mu$ (i) $\mathrm{T} \gamma(y)$.

Let $\mathrm{x} \in \mu_{\mathrm{a}}$ and $\mathrm{y} \in \gamma_{\mathrm{a}}$.

Then $\mathrm{x} \in \mu_{\mathrm{a}}$ and $\mathrm{y} \in \gamma_{\mathrm{a}} . \Rightarrow \mu(\mathrm{x}), \gamma(\mathrm{y}) \geq \mathrm{a}$.

Therefore $\mu(\mathrm{y}+\mathrm{x}-\mathrm{y})=\mu(\mathrm{x}) \geq \mathrm{a}$ for all $\mathrm{x} \in \mu_{\mathrm{a}}$ and $\mathrm{y} \in \gamma_{\mathrm{a}}$.

$$
\Rightarrow \mathrm{y}+\mathrm{x}-\mathrm{y} \in \mu_{\mathrm{a}} \text { for all } \mathrm{x} \in \mu_{\mathrm{a}} \text { and } \mathrm{y} \in \gamma_{\mathrm{a}} \text {. }
$$

Hence $\mu_{\mathrm{a}}$ is a normal L-subgroup of $\left(\gamma_{\mathrm{a}},+\right)$.

Now let $\mathrm{i} \in \mu_{\mathrm{a}}$ and $\mathrm{x}, \mathrm{y} \in \gamma_{\mathrm{a}}$

Then $\mu(\mathrm{i}) \geq \mathrm{a}$ and $\gamma(\mathrm{x}) \geq \mathrm{a}, \gamma(\mathrm{y}) \geq \mathrm{a}$.

since $\mu((x+i) y-x y) \geq \mu(i) \wedge \gamma(y) \geq a$.

Therefore $(x+i) y-x y \in \mu_{a}$ for all $i \in \mu_{a}$ and $x, y \in \gamma_{a}$.

Hence $\mu_{\mathrm{a}}$ is a right ideal of $\gamma_{\mathrm{a}}$.

Part (II): Let $\mu$ be L- left ideal of $\gamma$.

Let $\mathrm{x} \in \mu_{\mathrm{a}}$ and $\mathrm{y} \in \gamma_{\mathrm{a}}$.

Then $\mathrm{x} \in \mu_{\mathrm{a}}$ and $\mathrm{y} \in \gamma_{\mathrm{a}} \Rightarrow \mu(\mathrm{x}), \gamma(\mathrm{y}) \geq \mathrm{a}$.

Then $\mu(\mathrm{y}+\mathrm{x}-\mathrm{y}) \geq \mu(\mathrm{x}) \geq \mathrm{a}$ for all $\mathrm{x} \in \mu_{\mathrm{a}}$ and $\mathrm{y} \in \gamma_{\mathrm{a}}$.

Therefore $\mathrm{y}+\mathrm{x}-\mathrm{y} \in \mu_{\mathrm{a}}$ for all $\mathrm{x} \in \mu_{\mathrm{a}}$ and $\mathrm{y} \in \gamma_{\mathrm{a}}$.

Hence $\left(\mu_{\mathrm{a}},+\right)$ is a normal L-subgroup of $\left(\gamma_{\mathrm{a}},+\right)$.

Now let $\mathrm{y} \in \mu_{\mathrm{a}}$ and $\mathrm{x} \in \gamma_{\mathrm{a}}$

Since $\mu(x y) \geq \gamma(x) \wedge \mu(y)$.

Therefore $\mu(\mathrm{xy}) \geq \gamma(\mathrm{x}) \wedge \mu(\mathrm{y}) \geq \mathrm{a}$.

Thus $\mathrm{xy} \in \mu_{\mathrm{a}}$ for all $\mathrm{y} \in \mu_{\mathrm{a}}$ and $\mathrm{x} \in \gamma_{\mathrm{a}}$.

Hence $\mu_{a}$ is a left ideal of $\gamma_{a}$.

Remark (3.11): The converse of the theorem is true only when $\mu \in \mathrm{L}^{\mathrm{R}}$ is a normal Lsubgroup of $(\mathrm{R},+)$.

Theorem (3.12): Let $\mu \in \mathrm{L}^{\mathrm{R}}, \gamma \in \mathrm{L}(\mathrm{R})$ and $\mathrm{L}$ be a chain. Then a necessary condition for $\mu$ to 
be a L-right (resp.L-left) ideal of $\gamma$ is that for every a $\in \mathrm{L} \backslash\{1\}, \mu_{[\mathrm{a}]}$ is a right (resp. left) ideal of $\gamma_{[\mathrm{a}]}$.

Proof: Part (I): Let $\mu$ be a L-right ideal of $\gamma$.Then

(i) $\mu(0)=1$ implies that $0 \in \mu_{[a]}$ for every $a \in L \backslash\{1\}$.

(ii) $\mu(-\mathrm{x}) \geq \mu(\mathrm{x})$ for $\mathrm{x} \in \mu_{[\mathrm{a}]}$ implies that $-\mathrm{x} \in \mu_{[\mathrm{a}]}$.

(iii) Let $\mathrm{x}, \mathrm{y} \in \mu_{[\mathrm{a}]}$. Then $\mu(\mathrm{x})>\mathrm{a}, \mu(\mathrm{y})>\mathrm{a}$.

But $\mathrm{L}$ is a chain, therefore either $\mu(\mathrm{x}) \geq \mu(\mathrm{y})$ or $\mu(\mathrm{y}) \geq \mu(\mathrm{x})$.

Assume that $\mu(\mathrm{y}) \geq \mu(\mathrm{x})$.

As $\mu(\mathrm{x}+\mathrm{y}) \geq \mu(\mathrm{x}) \wedge \mu(\mathrm{y})=\mu(\mathrm{x})>$ a. Therefore $\mathrm{x}+\mathrm{y} \in \mu_{[\mathrm{aa}]}$ for all $\mathrm{i} \in \mathrm{x}, \mathrm{y} \in \mu_{[\mathrm{a}]}$.

Hence $\mu_{[a]}$ is a L-subgroup of $R$.

(iv) If $\mu_{[a]}$ is not normal then for some $a \in L \backslash\{1\}$, there exists $y \in R$ and $x \in \mu_{[a]}$ such that $\mathrm{y}+\mathrm{x}-\mathrm{y} \notin \mu_{[\mathrm{a}]}$. Thus $\mu(\mathrm{x})>\mathrm{a}$ and $\mu(\mathrm{y}+\mathrm{x}-\mathrm{y}) \leq \mathrm{a}$.

Hence $\mu(y+x-y)<\mu(x)$ and hence $\mu$ is not normal which is a contradiction.

Thus $\mu_{[\mathrm{a}]}$ is a normal subgroup of $\mathrm{R}$ for all $\mathrm{a} \in \mathrm{L} \backslash\{1\}$.

(v) Again if $\mu_{[a]}$ is not a right ideal of $\gamma_{[a]}$ then for some $\mathrm{a} \in \mathrm{L} \backslash\{1\}$, there exists $\mathrm{x}, \mathrm{y} \in \mathrm{R}$ and $\mathrm{i} \in \mu_{[\mathrm{a}]}$ such that $(\mathrm{x}+\mathrm{i}) \mathrm{y}-\mathrm{xy} \notin \mu_{[\mathrm{a}]}$

Thus $\mu(\mathrm{i})>\mathrm{a}$ and $\mu((\mathrm{x}+\mathrm{i}) \mathrm{y}-\mathrm{xy}) \leq \mathrm{a}$.

This implies that $\mu$ is not L-right ideal.

Thus we get a contradiction.

Hence $\mu((x+i) y-x y)>$ a for all $i \in \mu_{[a]}$ and $x, y \in \gamma_{[a]}$.

Hence $\mu_{[\mathrm{a}]}$ is a right ideal of $\gamma_{[\mathrm{a}]}$.

Part (II): Let $\mu$ be a L-left ideal of $\gamma$.

Then as in part $(\mathrm{I}),\left(\mu_{[\mathrm{a}]},+\right)$ is a normal L-subgroup of $(\mathrm{R},+)$.

Again if $\mu_{[a]}$ is not a left ideal of $\gamma_{[a]}$ then for some $a \in L \backslash\{1\}$, there exists $y \in \mu_{[a]}$ and $\mathrm{x} \in \gamma_{[\mathrm{a}]}$ such that $\mathrm{xy} \notin \mu_{[\mathrm{a}]}$.

Then $\mu(y)>a$ and $\mu(x y) \leq a$.Thus $\mu(x y)<\mu(y)$

Therefore $\mathrm{xy} \notin \mu_{[\mathrm{a}]}$ for $\mathrm{y} \in \mu_{[\mathrm{a}]}, \mathrm{x} \in \gamma_{[\mathrm{a}]}$, which is a contradiction.

Hence $\mu_{[\mathrm{a}]}$ is a right ideal of $\gamma_{[\mathrm{a}]}$.

Theorem (3.13): Let $\mu \in \mathrm{L}^{\mathrm{R}}$ and $\gamma \in \mathrm{L}(\mathrm{R})$ and $\mathrm{L}$ be dense. Then a sufficient condition for $\mu$ to be a L-right (resp.L-left) ideal of $\gamma$ is that for every $\mathrm{a} \in \mathrm{L} \backslash\{1\}, \mu_{[\mathrm{a}]}$ is a right (resp. left) ideal of $\gamma_{[a]}$.

Proof: Part (I): Let us suppose that for every $\mathrm{a} \in \mathrm{L} \backslash\{1\}, \mu_{[\mathrm{a]}}$ is a right ideal of $\gamma_{[\mathrm{a}] \text {. }}$ 
(i) Clearly $\mu(0)=1$.

(ii) Take $\mathrm{a}<\mu(\mathrm{x})$. Then $\mathrm{x} \in \mu_{[\mathrm{a}]}$ implies $-\mathrm{x} \in \mu_{[\mathrm{a}]}$.

$$
\begin{aligned}
& \Rightarrow \mu(-x)>a \Rightarrow \mu(-x) \geq 1 \text { and } \mu(x)>a . \\
& \Rightarrow \mu(-x) \geq \mu(x) \text { for all } x \in \mu_{[a]} .
\end{aligned}
$$

(iii) Now suppose $\mathrm{x}, \mathrm{y} \in \mu_{[\mathrm{a}]}$

Let $\mu(\mathrm{x}) \wedge \mu(\mathrm{y})>\mathrm{a}$.

Therefore $\mu(\mathrm{x})>\mu(\mathrm{x}) \wedge \mu(\mathrm{y})$.

$$
\Rightarrow \mu(\mathrm{x})>\mathrm{a} \Rightarrow \mathrm{x} \in \mu_{[\mathrm{a}]} \text {.Similarly } \mathrm{y} \in \mu_{[\mathrm{a}]} \text {. }
$$

Hence $\mathrm{x}+\mathrm{y} \in \mu_{[\mathrm{a}]}$ and so $\mu(\mathrm{x}+\mathrm{y})>\mathrm{a}$.

Let $\mathrm{a}=\mu(\mathrm{x}) \wedge \mu(\mathrm{y})$.

If $\mathrm{a}=0$ then $\mu(\mathrm{x}+\mathrm{y}) \geq 0=\mu(\mathrm{x}) \wedge \mu(\mathrm{y})$.

If $a>0$ then for any $b \in L, b<a$ we observe that $\mu_{[b]}$ is a right ideal of $R$

and $\mathrm{x}, \mathrm{y} \in \mu_{[\mathrm{b}]}$, implies that $\mu(\mathrm{x}+\mathrm{y}) \in \mu_{[\mathrm{b}]}$.

i.e. $\mu(x+y)>b \Rightarrow \mu(x+y) \geq \vee\{b \mid b \in L, b<a\}$.

Since $\mathrm{L}$ is dense, $\vee\{\mathrm{b} \mid \mathrm{b} \in \mathrm{L}, \mathrm{b}<\mathrm{a}\}=\mathrm{a}$.

Therefore $\mu(x+y) \geq a=\mu(x) \wedge \mu$ (y) for all $x, y \in \mu_{[a]}$.

(iv) Now let $\mathrm{y} \in \gamma_{[\mathrm{a}]}$ and $\mathrm{x} \in \mu_{[\mathrm{a}]}$ and let $\mathrm{a}>0$.

Then for any $b \in L, b<a$ we observe that $\left(\mu_{[b]},+\right)$ is a normal subgroup of $(R,+), x \in \mu_{[b]}$, implies $\mu(\mathrm{y}+\mathrm{x}-\mathrm{y})>\mathrm{b}$.

Thus $\mu(y+x-y) \geq \vee\{b \mid b \in L, b<a\}$.

Since $\mathrm{L}$ is dense, $\vee\{\mathrm{b} \mid \mathrm{b} \in \mathrm{L}, \mathrm{b}<\mathrm{a}\}=\mathrm{a}$.

Therefore $\mu(y+x-y) \geq \mu(x)$ for all $i \in \mu_{[a]}, y \in \gamma_{[a]}$.

(v) Finally, let $i \in \mu_{[a]}$ and $x, y \in \gamma_{[a]}$.

If $a=0$ then clearly $\mu((x+i) y-x y) \geq \mu$ (i).

If $a>0$ then for any $b \in \mathrm{L}, \mathrm{b}<\mathrm{a}$ we observe that $\mu_{[\mathrm{b}]}$ is a right ideal of $\gamma_{[\mathrm{a}]}$ and $\mathrm{x} \in \mu_{[\mathrm{b}] \text {, }}$ implies $\mu((x+i) y-x y)>b$.

Hence $\mu((x+i) y-x y) \geq \vee\{b \mid b \in L, b<a\}$.

Since $\mathrm{L}$ is dense, $\vee\{\mathrm{b} \mid \mathrm{b} \in \mathrm{L}, \mathrm{b}<\mathrm{a}\}=\mathrm{a}$. 
Therefore $\mu((x+i) y-x y) \geq a=\mu(i) \wedge \gamma(y)$.

Hence $\mu((x+i) y-x y) \geq \mu(i) \wedge \gamma(y)$ for all $x, y, i \in R$.

Thus $\mu$ is a L-right ideal of $\gamma$.

Part (II): Let us suppose that $\mu_{[\mathrm{a}]}$ is left ideal of $\gamma_{[\mathrm{a}]}$ for every $\mathrm{a} \in \mathrm{L} \backslash\{1\}$

We shall prove the last condition which conforms that $\mu$ is a L-left ideal of $\gamma$.

Let $\mathrm{y} \in \mu_{[\mathrm{a}]}$ and $\mathrm{x} \in \gamma_{[\mathrm{a}]}$. Then $\mu(\mathrm{y})>\mathrm{a}$ and $\gamma(\mathrm{x})>\mathrm{a}$.

If $\mathrm{a}=0$ then clearly $\mu(\mathrm{xy}) \geq \gamma(\mathrm{x}) \wedge \mu(\mathrm{y})$.

If $a>0$ then for any $b \in L, b<a$ we observe that $\mu_{[b]}$ is a left ideal of $\gamma_{[a]}$ and $x \in \mu_{[b]}$ implies $\mu$ (xy) $>b$. Hence $\mu(x y) \geq \vee\{b \mid b \in L, b<a\}$.

Since $\mathrm{L}$ is dense, $\vee\{b \mid b \in L, b<a\}=a$.

Therefore $\mu(x y) \geq a=\gamma(x) \wedge \mu(y)$.

Hence $\mu(x y) \geq a=\gamma(x) \wedge \mu(y)$ for all $x, y \in R$.

Thus $\mu$ to be a L-left ideal of $\gamma$.

Theorem (3.14): Let $\gamma \in \mathrm{TL}(\mathrm{R})$ and $\mu$ be a TL-left ideal of $\gamma$.

Then $R \mu$ is a left ideal of $R \gamma$.

Proof: Let $\gamma \in T L(R)$ and $\mu$ be a TL-left ideal of $\gamma$.

$\mathrm{R} \mu=\{\mathrm{x} \in \mathrm{R} \mid \mu(\mathrm{x})=1\}$, similarly $\mathrm{R} \gamma=\{\mathrm{x} \in \mathrm{R} \mid \gamma(\mathrm{x})=1\}$.

We know that $\mu \leq \gamma$ and $\mathrm{a} \in \mathrm{L} \Rightarrow \mu_{[\mathrm{a}]} \subseteq \gamma_{[\mathrm{a}]}$. Therefore $\mathrm{R} \mu \subseteq \mathrm{R} \gamma$.

Now first we shall prove that $(R \mu,+)$ is a subgroup of $(R,+)$.

(i) Since $\mu(0)=1,0 \in R \mu$.

Hence $R \mu$ is a non-empty subset of $R$.

(ii) Let $\mathrm{x} \in \mathrm{R} \mu$.

Then $\mu(x)=1$ and $\mu(-x) \geq \mu(x)$ implies $\mu(-x)=1$.

Therefore $-\mathrm{x} \in \mathrm{R} \mu$ for all $\mathrm{x} \in \mathrm{R} \mu$.

(iii) Let $\mathrm{x}, \mathrm{y} \in \mathrm{R} \mu$.

Then $\mu(\mathrm{x}+\mathrm{y}) \geq \mu(\mathrm{x}) \mathrm{T} \mu(\mathrm{y}) \Rightarrow \mu(\mathrm{x}+\mathrm{y}) \geq 1 \mathrm{~T} 1=1$.

Therefore $\mathrm{x}+\mathrm{y} \in \mathrm{R} \mu$ for all $\mathrm{x}, \mathrm{y} \in \mathrm{R} \mu$.

Hence $(R \mu,+)$ is a subgroup of $(R,+)$.

(iv)Let $\mathrm{y} \in \mathrm{R}$ and $\mathrm{x} \in \mathrm{R} \mu$. 
Since $\mu(y+x-y) \geq \mu(x)$ and $\mu(x)=1, \mu(y+x-y)=1$.

Therefore $y+x-y \in R \mu$ for all $y \in R$ and $x \in R \mu$.

Hence $(\mathrm{R} \mu,+)$ is a normal subgroup of $(\mathrm{R},+)$.

Similarly $(\mathrm{R} \gamma,+)$ is also a normal subgroup of $(\mathrm{R},+)$.

Again since $\mathrm{R} \mu \subseteq \mathrm{R} \gamma,(\mathrm{R} \mu,+)$ is a normal subgroup of $(\mathrm{R} \gamma,+)$.

(v) Since $\mu$ is a TL-left ideal of $\gamma, \mu(x y) \geq \gamma(x) T \mu(y)$ for all $x, y \in R$.

Let $\mathrm{x} \in \mathrm{R} \mu$ and $\mathrm{r} \in \mathrm{R} \gamma$.

Then $\mu(\mathrm{x})=1$ and $\gamma(\mathrm{r})=1$.

Therefore $\mu(\mathrm{rx}) \geq \gamma(\mathrm{r}) \mathrm{T} \mu(\mathrm{x})=1$.

Hence $r x \in R \mu$ for all $r \in R \gamma$ and $x \in R \mu$.

i.e. $\mathrm{R} \gamma \mathrm{R} \mu \subseteq \mathrm{R} \mu$.

Hence $\mathrm{R} \mu$ is a left ideal of $\mathrm{R} \gamma$.

Similarly we can obtain the following theorem:

Theorem (3.15): Let $\gamma \in \mathrm{TL}(\mathrm{R})$ and $\mu$ be a TL-right ideal of $\gamma$.

Then $\mathrm{R} \mu$ is a right ideal of $\mathrm{R} \gamma$.

Theorem (3.16): Let $\mu \in \mathrm{TLI}_{1}(\mathrm{R})$ and $\gamma$ be a normal TL-subgroup of $(\mathrm{R},+)$. Then $\mu \mathrm{T} \gamma$ is a TL-left ideal of $\gamma$.

Proof: Let $\mu \in \mathrm{TLI}_{1}(\mathrm{R})$ and $\gamma \in \mathrm{TL}(\mathrm{R})$.

Clearly $\mu \mathrm{T} \gamma \leq \gamma$ and $\mu \mathrm{T} \gamma$ is a TL-subgroup of $(\mathrm{R},+)$.

Again $\mu \mathrm{T} \gamma(\mathrm{y}+\mathrm{x}-\mathrm{y})=\mu(\mathrm{y}+\mathrm{x}-\mathrm{y}) \mathrm{T} \gamma(\mathrm{y}+\mathrm{x}-\mathrm{y}) \geq \mu(\mathrm{x}) \mathrm{T} \gamma(\mathrm{x})=\mu \mathrm{T} \gamma(\mathrm{x})$.

Therefore $\mu \mathrm{T} \gamma(\mathrm{y}+\mathrm{x}-\mathrm{y}) \geq \mu \mathrm{T} \gamma(\mathrm{x})$ for all $\mathrm{x}, \mathrm{y} \in \mathrm{R}$.

$\operatorname{Next} \mu \mathrm{T} \gamma(\mathrm{xy})=\mu(\mathrm{xy}) \mathrm{T} \gamma(\mathrm{xy}) \geq \mu(\mathrm{y}) \mathrm{T} \gamma(\mathrm{x}) \mathrm{T} \gamma(\mathrm{y})=\gamma(\mathrm{x}) \mathrm{T}(\mu \mathrm{T} \gamma)(\mathrm{y})$ for all $\mathrm{x}, \mathrm{y} \in \mathrm{R}$.

Hence $\mu \mathrm{T} \gamma$ is a TL-left ideal of $\gamma$.

Similarly we can prove the following theorem:

Theorem (3.17): Let $\mu \in \mathrm{TLI}_{\mathrm{r}}(\mathrm{R})$ and $\gamma$ be a normal TL-subgroup of $(\mathrm{R},+)$. Then $\mu \mathrm{T} \gamma$ is a TL-left ideal of $\gamma$

Theorem (3.18): Let $\xi \in \mathrm{TL}(\mathrm{R})$ and $\mu, \gamma$ be two TL-left ideals of $\xi$.Then $\mu \wedge \gamma$ is a TLleft ideal of $\xi$.

Proof: Let $\xi \in \mathrm{TL}(\mathrm{R})$ and $\mu, \gamma$ be two TL-left ideals of $\xi$.

Since $\mu$ and $\gamma$ are TL-left ideals of $\xi, \mu \leq \xi, \gamma \leq \xi$ and so $\mu \wedge \gamma \leq \xi$. 
Hence $\mu \wedge \gamma$ is a TL-subgroup of $(\mathrm{R},+)$.

Again $(\mu \wedge \gamma)(y+x-y)=\mu(y+x-y) \wedge \gamma(y+x-y) \geq \mu(x) \wedge \gamma(x)=(\mu \wedge \gamma)(x), x \in R$.

$(\mu \wedge \gamma)(\mathrm{xy})=\mu(\mathrm{xy}) \wedge \gamma(\mathrm{xy}) \geq(\xi(\mathrm{x}) \mathrm{T} \mu(\mathrm{y})) \wedge(\xi(\mathrm{x}) \mathrm{T} \gamma(\mathrm{y}))$.

$$
=\xi(\mathrm{x}) \mathrm{T}(\mu(\mathrm{y}) \wedge \gamma(\mathrm{y}))=\xi(\mathrm{x}) \mathrm{T}(\mu \wedge \gamma)(\mathrm{y}) \text { for all } \mathrm{x}, \mathrm{y} \in \mathrm{R} .
$$

Hence $\mu \wedge \gamma$ is a TL-left ideal of $\xi$.

Similarly we can prove the following theorem:

Theorem (3.19): Let $\xi \in \mathrm{TL}(\mathrm{R})$ and $\mu, \gamma$ be two TL-right ideals of $\xi$. Then $\mu \wedge \gamma$ is a TLright ideal of $\xi$.

\section{Homomorphism}

The following definitions are well-known:

Definition (4.1): Let $R$ and $R^{\prime}$ be two near-rings. A function $f: R \rightarrow R^{\prime}$ is called a homomorphism if for all $\mathrm{x}, \mathrm{y} \in \mathrm{R}$

$$
\begin{aligned}
& \text { (i) } f(x+y)=f(x)+f(y), \\
& \text { (ii) } f(x y)=f(x) f(y) .
\end{aligned}
$$

We know that a one-one homomorphism is an isomorphism.

\section{Definition (4.2) Extension Principle:}

Let $\mathrm{X}$ and $\mathrm{Y}$ be two non-empty sets and $\mathrm{f}: \mathrm{X} \rightarrow \mathrm{Y}$ be a function. Then $\mathrm{f}$ induces two functions,

$\mathrm{f}: \mathcal{F}(\mathrm{X}) \rightarrow \mathcal{F}(\mathrm{Y})$ and $\mathrm{f}^{-1}: \mathcal{F}(\mathrm{Y}) \rightarrow \mathcal{F}(\mathrm{X})$ which are defined as follows:

1) $[\mathrm{f}(\mu)](\mathrm{y})=\sup _{\mathrm{x} \mid \mathrm{y}=\mathrm{f}(\mathrm{x})}\{\mu(\mathrm{x})\}$; if $\mathrm{y}=\mathrm{f}(\mathrm{x})$,

$$
=0 \text {; otherwise. }
$$

2) $\left[\mathrm{f}^{-1}(\gamma)\right](\mathrm{x})=\gamma(\mathrm{f}(\mathrm{x})$; for all $\gamma \in \mathcal{F}(\mathrm{Y})$.

In the following theorem we prove that the homomorphic image of TL-left (resp.right) ideal of $\mathrm{R}$ is a TL-left (resp.right) ideal of S:

Theorem (4.3): Let $\mathrm{f}: \mathrm{R} \rightarrow \mathrm{S}$ be a homomorphism of a near-ring $\mathrm{R}$ onto a near-ring $\mathrm{S}$ and $\mu \in \mathrm{TLI}_{\mathrm{r}}(\mathrm{R})\left(\operatorname{resp} . \mu \in \mathrm{TLI}_{\mathrm{l}}(\mathrm{R})\right)$. Then $\left.\mathrm{f}(\mu) \in \mathrm{TLI}_{\mathrm{r}}(\mathrm{S})\right)\left(\operatorname{resp} . \mu \in \mathrm{TLI}_{1}(\mathrm{~S})\right)$.

Proof: Let $\mathrm{f}: \mathrm{R} \rightarrow \mathrm{S}$ be a homomorphism of a near-ring $\mathrm{R}$ onto a near-ring $\mathrm{S}$.

Let $\mathrm{x}, \mathrm{y} \in \mathrm{S}$.

Part (I): Let $\mu \in \mathrm{TLI}_{\mathrm{r}}(\mathrm{R})$. 
(i) Clearly $\mathrm{f}(\mu)\left(0^{\prime}\right)=1$.

(ii) $\mathrm{f}(\mu)(-\mathrm{x})=\vee\{\mu(\mathrm{w}) \mid \mathrm{w} \in \mathrm{R}, \mathrm{f}(\mathrm{w})=-\mathrm{x}\}$.

$$
\begin{aligned}
& =\vee\{\mu(-w) \mid-w \in R, f(-w)=x\} . \\
& \geq \vee\{\mu(w) \mid w \in R, f(w)=x\} . \\
& =f(\mu)(x) \text { for all } x \in S .
\end{aligned}
$$

(ii) $f(\mu)(x-y)=\vee\{\mu(w) \mid w \in R, f(w)=x-y\}$

$$
\begin{aligned}
& \geq \vee\{\mu(\mathrm{u}-\mathrm{v}) \mid \mathrm{u}, \mathrm{v} \in \mathrm{R}, \mathrm{f}(\mathrm{u})=\mathrm{x}, \mathrm{f}(\mathrm{v})=\mathrm{y}\} \\
& \geq \vee\{\mu(\mathrm{u}) \mathrm{T} \mu(\mathrm{v}) \mid \mathrm{u}, \mathrm{v} \in \mathrm{R}, \mathrm{f}(\mathrm{u})=\mathrm{x}, \mathrm{f}(\mathrm{v})=\mathrm{y}\} \\
& \geq(\vee\{\mu(\mathrm{u})) \mid \mathrm{u} \in \mathrm{R}, \mathrm{f}(\mathrm{u})=\mathrm{x}\}) \mathrm{T}(\vee\{\mu(\mathrm{v}) \mid \mathrm{v} \in \mathrm{R}, \mathrm{f}(\mathrm{v})=\mathrm{y}\} \\
& =\mathrm{f}(\mu)(\mathrm{x}) \mathrm{T} \mathrm{f}(\mu)(\mathrm{y}) \text { for all } \mathrm{x}, \mathrm{y} \in \mathrm{S} .
\end{aligned}
$$

(iii) $\mathrm{f}(\mu)(\mathrm{y}+\mathrm{x}-\mathrm{y})=\vee\{\mu(w) \mid w \in R, f(w)=y+x-y\}$

$$
\begin{aligned}
& =\vee\{\mu(v+u-v) \mid u, v \in R, f(u)=x, f(v)=y\} . \\
& \geq \vee\{\mu(u) \mid u \in R, f(u)=x\} .
\end{aligned}
$$

Therefore $\mathrm{f}(\mu)(\mathrm{y}+\mathrm{x}-\mathrm{y}) \geq \vee\{\mu(\mathrm{u}) \mid \mathrm{u} \in \mathrm{R}, \mathrm{f}(\mathrm{u})=\mathrm{x}\}$.

i.e. $f(\mu)(y+x-y) \geq f(\mu)(x)$ for all $x, y \in S$.

Hence $f(\mu)(y+x-y) \geq f(\mu)(x)$ for all $x, y \in S$.

(v) $f(\mu)((x+i) y-x y)=\vee\{\mu(w) \mid w \in R, f(w)=(x+i) y-x y\}$.

$$
\begin{aligned}
& \geq \vee\{\mu((u+t) v-u v) \mid u, v, t \in R, f(u)=x, f(v)=y, f(t)=i\} . \\
& \geq \vee\{\mu(t) \mid t \in R, f(t)=i\} . \\
& =f(\mu)(i) \text { for all } x, y, i \in S .
\end{aligned}
$$

Hence $\mathrm{f}(\mu) \in \mathrm{TLI}_{\mathrm{r}}(\mathrm{S}) . \geq$

Part (II): Let $\mu \in \mathrm{TLI}_{1}$ (R). Then clearly

(vi) $f(\mu)(x y) \geq f(\mu)(y)$ for all $x, y \in S$.

Hence from (i), (ii), (iii), (iv) and (vi) $\mathrm{f}(\mu) \in \mathrm{TLI}_{1}(\mathrm{~S})$.

In the following theorem we discuss about the inverse images of TL-right/left ideals of R:

Theorem (4.4): Let $\mathrm{f}: \mathrm{R} \rightarrow \mathrm{S}$ be a homomorphism of a near-ring $\mathrm{R}$ into a near-ring $\mathrm{S}$ and $\gamma \in \operatorname{TLI}_{\mathrm{r}}(\mathrm{S})\left(\right.$ resp. $\left.\in \in \mathrm{TLI}_{1}(\mathrm{~S})\right)$. Then $\mathrm{f}^{-1}(\gamma) \in \mathrm{TLI}_{\mathrm{r}}(\mathrm{R})\left(\operatorname{resp} \mathrm{f}^{-1}(\gamma) \in \mathrm{TLI}_{1}(\mathrm{R})\right.$. 
Proof: Let $f: \mathrm{R} \rightarrow \mathrm{S}$ be a homomorphism of a near-ring $\mathrm{R}$ onto a near-ring $\mathrm{S}$.

Part (I): Let $\gamma \in \operatorname{TLI}_{\mathrm{r}}(\mathrm{S})$.

(i) $\mathrm{f}^{-1}(\gamma)(0)=\gamma(\mathrm{f})(0)=\gamma\left(0^{\prime}\right)=1$.

(ii) $\mathrm{f}^{-1}(\gamma)(-\mathrm{x})=\gamma(\mathrm{f})(-\mathrm{x})=\gamma(-\mathrm{f}(\mathrm{x})) \geq \gamma(\mathrm{f}(\mathrm{x}))=\mathrm{f}^{-1}(\gamma)(\mathrm{x})$ for all $\mathrm{x} \in \mathrm{R}$.

(iii) $f^{-1}(\gamma)(x+y) \geq\left(f^{-1}(\gamma)(x)\right) T\left(f^{-1}(\gamma)(y)\right)$ for all $x, y \in R$.

(iv) $\mathrm{f}^{-1}(\gamma)(\mathrm{y}-\mathrm{x}+\mathrm{y})=\gamma(\mathrm{f}(\mathrm{y}+\mathrm{x}-\mathrm{y})) \geq \gamma(\mathrm{f}(\mathrm{x}))=\mathrm{f}^{-1}(\gamma)(\mathrm{x})$ for all $\mathrm{x}, \mathrm{y} \in \mathrm{R}$.

$(v) f^{-1}(\gamma)((x+i) y-x y)=\gamma(f((x+i) y-x y)) \geq f^{-1} \gamma$ (i) for all $x, y, i \in R$.

Hence $\mathrm{f}^{-1}(\gamma) \in \mathrm{TLI}_{\mathrm{r}}(\mathrm{R})$.

Part (II) : Let $\gamma \in \mathrm{TLI}_{1}(\mathrm{~S})$.

$(v i) f^{-1}(\gamma)(x y)=\gamma(f(x y))=\gamma(f(x) f(y)) \geq \gamma(f(y))=f^{-1}(\gamma)(y)$ for all $x, y \in R$.

Hence from (i), (ii), (iii), (iv) and (vi) $\mathrm{f}^{-1}(\gamma) \in \mathrm{TLI}_{1}(\mathrm{R})$.

For $\mu \in \mathrm{L}^{\mathrm{R}}$ and $\gamma \in \mathrm{TL}(\mathrm{R})$ then $\mathrm{f}(\mu)$ is a TL-left ideal of $\mathrm{f}(\gamma)$ under the following conditions:

Theorem (4.5): Let $\mathrm{f}: \mathrm{R} \rightarrow \mathrm{S}$ be a homomorphism of a near-ring $\mathrm{R}$ onto a near-ring $\mathrm{S}$.

Let $\gamma \in \mathrm{TL}(\mathrm{R})$ and $\mu$ a TL-left ideal of $\gamma$.Then $\mathrm{f}(\mu)$ is a TL-left ideal of $\mathrm{f}(\gamma)$.

Proof: Let $\mathrm{f}: \mathrm{R} \rightarrow \mathrm{S}$ be a homomorphism of a near-ring $\mathrm{R}$ onto a near-ring $\mathrm{S}$.

Since $\mu \leq \gamma, f(\mu) \leq f(\gamma)$.

Part (I): Let $\mu$ be a TL- right ideal of $\gamma$.

Also both $f(\mu)$ and $f(\gamma)$ are TL-subgroups of $(R,+)$.

Let $\mathrm{x}, \mathrm{y} \in \mathrm{S}$. Then

$$
\begin{aligned}
& f(\mu)(y+x-y)=\vee\{\mu(w) \mid w \in R, f(w)=y+x-y\} . \\
& \geq \vee\{\mu(v+u-v) \mid u, v \in R, f(u)=x, f(v)=y\} . \\
& =\vee\{\mu(\mathrm{u}) \mid \mathrm{u} \in \mathrm{R}, \mathrm{f}(\mathrm{u})=\mathrm{x}\} \text {. } \\
& =f(\mu)(x) \text { for all } x, y \in R \text {. } \\
& \mathrm{f}(\mu)((x+i) y-x y)=\vee\{\mu(w) \mid w \in R, f(w)=(x+i) y-x y\} \\
& \geq \vee\{\mu((u+t) v-u v) \mid u, v, t \in R, f((u+t) v-u v))=(x+i) y-x y\} \\
& \geq \vee\{\mu(\mathrm{t}) \mathrm{T} \gamma(\mathrm{v}) \mid \mathrm{t}, \mathrm{y} \in \mathrm{R}, \mathrm{f}(\mathrm{t})=\mathrm{i}, \mathrm{f}(\mathrm{y})=\mathrm{v}\} \\
& =(\vee\{\mu(\mathrm{t})) \mid \mathrm{t} \in \mathrm{R}, \mathrm{f}(\mathrm{t})=\mathrm{i}\}) \mathrm{T}(\vee\{\gamma(\mathrm{v}) \mid \mathrm{y} \in \mathrm{R}, \mathrm{f}(\mathrm{y})=\mathrm{v}\}) \text {. } \\
& =f(\mu)(i) T f(\gamma)(y) \text {. }
\end{aligned}
$$


Thus $f(\mu)((x+i) y-x y) \geq f(\mu)(i) T f(\gamma)(y)$, for all $x, y, i \in R$.

Hence $f(\mu)$ is a TL-right ideal of $f(\gamma)$.

Part (II): Let $\mu$ be a TL- left ideal of $\gamma$.

$\mathrm{f}(\mu)(\mathrm{xy})=\vee\{\mu(w) \mid w \in R, f(w)=x y\}$.

$\geq \vee\{\mu(u v) \mid u, v \in R, f(u)=x, f(v)=y\}$.

$\geq \vee\{\gamma(\mathrm{u}) \mathrm{T} \mu(\mathrm{v}) \mid \mathrm{u}, \mathrm{v} \in \mathrm{R}, \mathrm{f}(\mathrm{u})=\mathrm{x}, \mathrm{f}(\mathrm{v})=\mathrm{y}\}$.

$=(\vee\{\gamma(\mathrm{u}) \mid \mathrm{u} \in \mathrm{R}, \mathrm{f}(\mathrm{u})=\mathrm{x}\}) \mathrm{T}(\vee\{\mu(\mathrm{v}) \mid \mathrm{v} \in \mathrm{R}, \mathrm{f}(\mathrm{v})=\mathrm{y}\})$.

$=f(\gamma)(x) T f(\mu)(y)$ for all $x, y \in R$.

Hence $f(\mu)$ is a TL-left ideal of $f(\gamma)$.

For $\mu \in \mathrm{L}^{\mathrm{R}}$ and $\gamma \in \mathrm{TL}(\mathrm{R})$ then $\mathrm{f}(\mu)$ is a TL-left ideal of $\mathrm{f}(\gamma)$, this we prove in the following theorem:

Theorem (4.6): Let $f: R \rightarrow S$ be a homomorphism of a near-rings and $\gamma \in \mathrm{TL}(\mathrm{S}), \mu$ be TLright (resp.left) ideal of $\gamma$. Then $\mathrm{f}^{1}(\mu)$ is a TL-right(resp.left) ideal of $f^{-1}(\gamma)$.

Proof: Let $\mathrm{f}: \mathrm{R} \rightarrow \mathrm{S}$ be a homomorphism of a near-rings.

Clearly $\mu \leq \gamma \Rightarrow \mathrm{f}^{-1}(\mu) \leq \mathrm{f}^{-1}(\gamma)$.

As proved earlier $\mathrm{f}^{-1}(\mu)$ and $\mathrm{f}^{-1}(\gamma)$ are TL-subgroups of $\mathrm{R}$ and $\mathrm{f}^{-1}(\mu) \leq \mathrm{f}^{-1}(\gamma)$.

Part (I): Let $\mu$ be a TL- right ideal of $\gamma$ and $x, y \in R$. Then

(i) $\mathrm{f}^{-1}(\mu)(0)=\mu(\mathrm{f})(0)=\gamma\left(0^{\prime}\right)=1$.

(ii) $\mathrm{f}^{-1}(\mu)(-\mathrm{x})=\mu(\mathrm{f})(-\mathrm{x})=\mu(-\mathrm{f}(\mathrm{x})) \geq \mu(\mathrm{f}(\mathrm{x}))=\mathrm{f}^{-1}(\mu)(\mathrm{x})$ for all $\mathrm{x} \in \mathrm{R}$.

(iii) $\mathrm{f}^{-1}(\mu)(\mathrm{x}-\mathrm{y})=\mu(\mathrm{f})(\mathrm{x}-\mathrm{y}) \geq \mu(\mathrm{f}(\mathrm{x})) \mathrm{T} \mu(\mathrm{f}(\mathrm{y}))=\mathrm{f}^{-1}(\mu)(\mathrm{x}) \mathrm{T} \mathrm{f}^{-1}(\mu)(\mathrm{y})$.

i.e. $f^{1}(\mu)(x-y) \geq f^{1}(\mu)(x) T f^{1}(\mu)(y)$ for all $x, y \in R$.

(iv) $\mathrm{f}^{-1}(\mu)(\mathrm{y}+\mathrm{x}-\mathrm{y})=\mu(\mathrm{f})(\mathrm{y}+\mathrm{x}-\mathrm{y})=\mu(\mathrm{f}(\mathrm{y})+\mathrm{f}(\mathrm{x})-\mathrm{f}(\mathrm{y})) \geq \mu(\mathrm{f}(\mathrm{x}))=\mathrm{f}^{-1}(\mu)(\mathrm{x})$.

i.e. $f^{-1}(\mu)(y+x-y) \geq f^{-1}(\mu)(x)$ for all $x, y \in R$.

$(v) f^{-1}(\mu)((x+i) y-x y)=\mu(f)((x+i) y-x y)$.

$$
\begin{aligned}
& =\mu((f(x)+(f(i))(f(y)-(f(x)(f(y)) . \\
\geq \mu(f(i)) . & \\
= & f^{-1}(\mu)(i) .
\end{aligned}
$$

Thus $\mathrm{f}^{-1}(\mu)((\mathrm{x}+\mathrm{i}) \mathrm{y}-\mathrm{xy}) \geq \mu(\mathrm{f}(\mathrm{i}))=\mathrm{f}^{-1}(\mu)(\mathrm{i})$ for all $\mathrm{x}, \mathrm{y}, \mathrm{i} \in \mathrm{R}$.

Hence $f^{-1}(\mu)$ is a right ideal of $f^{-1}(\gamma)$.

Part (II):Let $\mu$ be a TL- left ideal of $\gamma$.Then 
$(v i) f^{-1}(\mu)(x y)=\mu(f(x y))=\mu(f(x) f(y)) \geq \gamma\left(f(x) T \mu(f(y))=\left(f^{-1}(\gamma)(x)\right) T\left(f^{-1}(\mu)(y)\right)\right.$.

i.e. $f^{1}(\mu)(x y) \geq\left(f^{1}(\gamma)(x)\right) T\left(f^{-1}(\mu)(y)\right)$ for all $x, y \in R$.

Hence from (i), (ii) (iii) (iv) and (vi) $\mathrm{f}^{-1}(\mu)$ is a TL-left ideal of $\mathrm{f}^{-1}(\gamma)$.

Theorem (4.7): If an L-subset $\mu^{*}$ of $R / \mu$ is defined by $\mu^{*}(x+\mu)=\mu(x)$ for all $x \in R$ then $\mu^{*} \in \operatorname{TLI}(\mathrm{R})$.

Proof: Now let us define a function $\mathrm{f}: \mathrm{R} / \mu \rightarrow \mathrm{R} / \mathrm{R} \mu$ by

$\mathrm{f}(\mathrm{x}+\mu)=\mathrm{x}+\mathrm{R} \mu$ for all $\mathrm{x} \in \mathrm{R}$.

We shall prove that $f$ is an onto isomorphism.

(1) $f\left((x+\mu){ }_{T}(y+\mu)\right)=f((x+y)+\mu)=(x+y)+R \mu=(x+R \mu)+(y+R \mu)$

$$
=\mathrm{f}(\mathrm{x}+\mu)+\mathrm{f}(\mathrm{y}+\mu)) \text {. }
$$

(2) $f((x+\mu) *(y+\mu))=f(x y+\mu)=x y+R \mu=(x+R \mu) *(y+R \mu)$.

$$
=f(x+\mu) * f(y+\mu) \text {. }
$$

(3) Let $f(x+\mu)=f(y+\mu)$ where $x, y \in R$.

Then $\mathrm{f}(\mathrm{x}+\mu)=\mathrm{f}(\mathrm{y}+\mu) \Rightarrow \mathrm{x}+\mathrm{R} \mu=\mathrm{y}+\mathrm{R} \mu \Rightarrow \mathrm{x}-\mathrm{y} \in \mathrm{R} \mu \Rightarrow \mu(\mathrm{x}-\mathrm{y})=\mu(0)$

$$
\Rightarrow \mu(\mathrm{x})=\mu(\mathrm{y}) \Rightarrow \mathrm{x}=\mathrm{y} \Rightarrow \mathrm{x}+\mu=\mathrm{y}+\mu .
$$

Hence $\mathrm{f}$ is an isomorphism.

(4) We observe that for all $\mathrm{x}+\mathrm{R} \mu \in \mathrm{R} / \mathrm{R} \mu, \mathrm{x} \in \mathrm{R}$ there exists $\mathrm{x}+\mu \in \mathrm{R} / \mu$ such that $\mathrm{f}(\mathrm{x}+$ $\mu)=x+R \mu$ for all $x \in R$.

Therefore $\mathrm{f}$ is an onto isomorphism.

(5) An L-subset $\mu^{*}$ of $R / \mu$ is defined by

$\mu^{*}(x+\mu)=\mu(x)$ for all $x \in R$. Then

(i) $\mu^{*}(\mu)=\mu^{*}(0+\mu)=\mu(0)=1$.

(ii) $\mu^{*}(-\mathrm{x}+\mu)=\mu(-\mathrm{x}) \geq \mu(\mathrm{x})=\mu^{*}(\mathrm{x}+\mu)$ for all $\mathrm{x} \in \mathrm{R}$.

(iii) $\mu^{*}\left((x+\mu)+{ }_{T}(y+\mu)\right)=\mu^{*}((x+y)+\mu)=\mu(x+y)$.

$$
\geq \mu(\mathrm{x}) \mathrm{T} \mu(\mathrm{y})=\mu^{*}(\mathrm{x}+\mu) \mathrm{T} \mu^{*}(\mathrm{y}+\mu) \text { for all } \mathrm{x}, \mathrm{y} \in \mathrm{R} \text {. }
$$

(iv) $\left.\mu^{*}\left((y+\mu)+_{T}(x+\mu)+{ }_{T}(-y+\mu)\right)=\mu^{*}((y+x)+\mu)+{ }_{T}(-y+\mu)\right)$.

$$
\begin{aligned}
& \left.=\mu^{*}((y+x)+\mu)+{ }_{T}(-y+\mu)\right) . \\
& =\mu^{*}((y+x-y)+\mu) . \\
& =\mu(y+x-y) \\
& \geq \mu(x) .
\end{aligned}
$$




$$
=\mu^{*}(\mathrm{x}+\mu) \text { for all } \mathrm{x}, \mathrm{y} \in \mathrm{R} \text {. }
$$

(iv) $\mu^{*}((\mathrm{x}+\mu) *(\mathrm{y}+\mu))=\mu^{*}(\mathrm{xy}+\mu)=\mu(\mathrm{xy}) \geq \mu(\mathrm{y})=\mu^{*}(\mathrm{y}+\mu)$ for all $\mathrm{x}, \mathrm{y} \in \mathrm{R}$.

(v) $\left.\mu^{*}\left[\left((x+\mu)+_{T}(a+\mu)\right)\right) *(y+\mu)-(x+\mu) *(y+\mu)\right]$

$$
\begin{aligned}
& =\mu^{*}[(x+a) *(y+\mu)-(x+\mu) *(y+\mu)] \\
& \left.=\mu^{*}[(x+a) y+\mu)-(x y+\mu)\right] . \\
& \left.=\mu^{*}[((x+a) y-x y)+\mu)\right] . \\
& =\mu((x+a) y-x y) . \\
& \geq \mu(a) . \\
& =\mu^{*}(a+\mu) \text { for all } x, y, a \in R .
\end{aligned}
$$

Therefore $\mu^{*}$ is a TL-left as well TL-right ideal of R.

\section{References}

[1] S. Abou-Zaid, On Fuzzy Subnear-rings and Ideals, Fuzzy Sets and Systems 44 (1991), 139-146.

[2] M. Akgul, Properties of Fuzzy Groups, Journal of Mathematical Analysis and Applications 133(1988), 93-100.

[3] J.M. Anthoy and H. Sherwood, Fuzzy Groups Redefined, Journal of Mathematical Analysis and Applications 69(1979), 124-130.

[4] M. Asaad and S. Abou-Zaid, A Contribution to the Theory of Fuzzy Subgroups, Fuzzy Sets and Systems 77(1996), 355-369.

[5] S.C. Cheng, John N. Mordeson and Yu Yandong, Lecture Notes in Fuzzy Mathematics and Computer Science, Elements of L-Algebra, Centre for Research in Fuzzy Mathematics and Computer Science, Creighton University, Omaha, Nebraska 68178, USA, 1994.

[6] P.S. Das, Fuzzy Groups and Level Subgroups, Journal of Mathematical Analysis and Applications 84(1981), 264-269.

[7] V.N. Dixit, S.K. Bhambri and Pratibha Kumar, Level Subgroups and Union of Fuzzy Subgroups, Fuzzy Sets and Systems 37(1990), 359-371.

[8] T. K. Dutta and B. K. Biswas, Fuzzy Ideals of Near-Ring, Bull. Cal. Math Soc. 89 (1997), 447-456.

[9] J.A. Goguen, L-FuzzySets, Journal of Mathematical Analysis and Applications18 (1967), 145-174.

[10] Pilz Gunter, Near-Rings, North-Holland, Amsterdam, 1983.

[11] W. Liu, Fuzzy Invariant Subgroups and Fuzzy Ideals, Fuzzy Sets and Systems 8(1982), 133-139.

[12] J.D.P. Meldrum, Near-Rings and their Links with Groups, Pitman, London.

[13] A. Rosenfeld, Fuzzy Groups, Journal Mathematical Analysis and Applications, 35 (1971), 512-517.

[14] J.D. Yadav and Y.S. Pawar, TL-ideals of Near-rings, communicated.

[15] L.A. Zadeh, Fuzzy Sets, Inform. and Control 8(1965), 338-353. 